VIDEOS IN CLINICAL MEDICINE

SUMMARY POINTS

Julie R. Ingelfinger, M.D., Editor

\section{Carotid Sinus Massage}

\author{
Mathieu Pasquier, M.D., Mathieu Clair, M.D., Etienne Pruvot, M.D., \\ Olivier Hugli, M.D., M.P.H., and Pierre-Nicolas Carron, M.D.
}

The following text summarizes information provided in the video.

\section{OVERVIEW}

Carotid sinus massage is a major diagnostic test for carotid sinus hypersensitivity, which may be manifested as dizziness or syncope. Carotid sinus massage is also used in emergency settings to diagnose or treat paroxysmal supraventricular tachycardia. ${ }^{1,2}$ This supplement reviews the information provided in the video on the indications for carotid sinus massage, the contraindications, and the equipment and techniques required to perform the procedure safely in adults.

\section{INDICATIONS}

Carotid sinus massage can be performed at the bedside and is indicated for the evaluation of syncope in patients older than 40 years of age for whom a cause is not identified on initial examination. ${ }^{3}$ Carotid sinus massage is also recommended for the initial treatment of hemodynamically stable paroxysmal supraventricular tachycardia. In addition, carotid sinus massage may help to clarify the type and origin of narrow-complex tachycardia. ${ }^{4}$

The carotid sinus senses changes in arterial blood pressure by means of baroreceptors - interwoven nerve endings of sensory neurons that extend throughout the adventitia along the first segment of the internal carotid artery, just above the carotid bifurcation. ${ }^{5}$ Baroreceptors are stimulated by the stretching of the bloodvessel wall. In response to high blood pressure, the firing rate of the nerve fibers increases, inhibiting the sympathetic nervous system and stimulating the parasympathetic nervous system through a centrally acting mechanism; the result is a decrease in blood pressure and heart rate.

\section{CONTRAINDICATIONS}

Carotid sinus massage is contraindicated in patients who are at risk for stroke due to carotid artery disease. According to the joint guidelines of the American Heart Association and the American College of Cardiology, carotid sinus massage should be avoided in patients who have had a transient ischemic attack or stroke within the preceding 3 months or who have clinically significant ipsilateral carotid stenosis or bruit. ${ }^{3,6}$ A carotid bruit is not a sensitive indicator of carotid artery disease. Thus, in patients who are at high risk for stroke, such as those with peripheral artery disease or coronary heart disease, it may be helpful for an experienced clinician to perform carotid Doppler ultrasonography before carotid massage is attempted. Complications from previous massage, myocardial infarction in the preceding 3 months, or any history of ventricular arrhythmia are also contraindications. $^{7}$
From Lausanne University Hospital, Lausanne, Switzerland.

N Engl J Med 2017;377:e21. DOI: $10.1056 /$ NEJMvcm1313338 Copyright $\odot 2017$ Massachusetts Medical Society. 


\section{EQUIPMENT}

The equipment needed to perform carotid sinus massage includes a stethoscope, a cardiac monitor that can both record continuously and obtain repeated bloodpressure measurements, and an electrocardiogram (ECG) machine. Make sure that the drugs and equipment necessary for emergency cardiopulmonary resuscitation and a defibrillator are readily available. An intravenous catheter should be in place when supraventricular tachycardia is being evaluated, and although no recommendations exist regarding the necessity of a catheter when evaluating syncope, the same cautious recommendation may apply. If carotid sinus massage is performed for the evaluation of syncope, it is generally recommended that the test be repeated with the patient in an upright or sitting position if the result of carotid sinus massage is negative when the patient is in the supine position. ${ }^{8}$

\section{PREPARATION}

Wash your hands, and explain the procedure to the patient. Confirm the patient's identity, the indication for carotid sinus massage, and the absence of contraindications. Place the patient in the supine position, with the head slightly extended. Examine the patient to determine the location of the landmarks you will use when performing the procedure. Before starting the procedure, auscultate the carotid artery to rule out any ipsilateral carotid bruit. Gently place the bell of the stethoscope over the carotid artery and ask the patient to stop breathing while you auscultate the artery. If you have not already done so, monitor the heart rate and start intermittent blood-pressure measurements. Ask an assistant to monitor the ECG tracing simultaneously.

\section{LOCATION OF LANDMARKS}

The carotid sinus is located at the bifurcation of the common carotid artery, which is found at the level of the thyroid cartilage, below the angle of the mandible and medial to the sternocleidomastoid muscle. Begin by locating the thyroid cartilage. The carotid sinus is located at the upper border of the thyroid cartilage, medial to the sternocleidomastoid muscle (Fig. 1). Hold your index and middle fingers together and slide them from the thyroid cartilage posteriorly, toward the patient's spine, until you feel the carotid pulse.

\section{PROCEDURE}

Before performing carotid sinus massage, inform the patient that you are about to begin the procedure and ask an assistant to start a continuous printout of the ECG tracing. Apply firm and steady pressure to the right or left carotid sinus, but do not occlude the artery and do not apply pressure to both sinuses at the same time. Steady pressure is recommended because it may be more reproducible than intermittent pressure. ${ }^{9}$ Tell the assistant when you begin to apply pressure so that this moment can be precisely marked on the ECG printout. Observe the patient and the monitor during the procedure. Apply pressure for at least 5 seconds but not more than 10 seconds. Stop the ECG printout at the end of the procedure, and carefully examine the electrocardiographic response to the carotid sinus massage.

A normal response to carotid sinus massage is a transient decrease in the sinus rate and a slowing of atrioventricular nodal conduction. Carotid sinus massage may also induce a decrease in the amplitude of the $\mathrm{P}$ wave. The typical bloodpressure response to carotid sinus massage may be mild hypotension induced by a decrease in vascular tone. ${ }^{4}$

In evaluation of the cause of syncope, a ventricular pause lasting 3 seconds or more or a drop in systolic blood pressure of $50 \mathrm{~mm} \mathrm{Hg}$ or more defines carotid

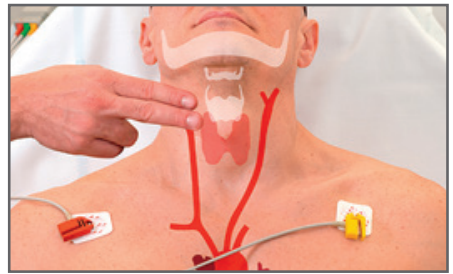

Figure 1. Location of the Carotid Sinus. The carotid sinus is located at the upper border of the thyroid cartilage, medial to the sternocleidomastoid muscle. During carotid sinus massage, the second and third fingers should be placed as shown. 
sinus hypersensitivity (Fig. 2). To diagnose the carotid sinus syndrome, it is necessary to reproduce the symptoms associated with syncope and to record a ventricular pause that lasts 3 seconds or more or a drop in systolic blood pressure of $50 \mathrm{~mm} \mathrm{Hg}$ or more. ${ }^{3}$

There are three possible responses to carotid sinus massage. The cardioinhibitory response is defined as a pause of 3 seconds or more without a drop in blood pressure of $50 \mathrm{~mm} \mathrm{Hg}$ or more, the vasodepressor response is defined as a decrease in blood pressure of $50 \mathrm{~mm} \mathrm{Hg}$ or more without a pause of 3 seconds or more, and the mixed response is defined as the association of a pause of 3 seconds or more with a drop in blood pressure of $50 \mathrm{~mm} \mathrm{Hg}$ or more. ${ }^{8}$ Characterization of the type of carotid sinus syndrome is useful not only for the purpose of diagnosis but also for the purpose of guiding further clinical management, since only the cardioinhibitory syndrome and, to a lesser degree, the mixed form of carotid sinus syndrome are likely to respond to cardiac pacing. ${ }^{10,11}$ If the initial massage of the carotid sinus on one side of the body does not produce a diagnostic response or a complication, massage can be performed on the opposite carotid sinus when the patient is ready and the heart rate and blood pressure have returned to stable baseline values.

If you are performing carotid sinus massage for the evaluation of unexplained syncope and the procedure has been performed on each carotid sinus with inconclusive results, it is advisable to move the patient from a supine position to an upright position on a tilt table and to perform the massage again. With the patient strapped in the upright position, the sensitivity of the test is increased and the magnitude of the vasodepressor component can be more easily evaluated. However, carotid sinus massage with the patient in the upright position should be performed only in a specialized setting, generally with the patient secured on a tilt table in order to prevent falls and with the use of continuous, noninvasive bloodpressure monitoring.

When carotid sinus massage is used to treat atrioventricular nodal reentrant tachycardia or tachycardia mediated by an accessory pathway, the restoration of sinus rhythm indicates that the procedure has been successful (Fig. 3). In some instances, carotid sinus massage may produce a transient slowing of the ventricular rate that can unmask underlying atrial activity, allowing a diagnosis of, for example, an underlying hidden atrial flutter (Fig. 4). You can perform a massage on the opposite side if the massage on the first side did not produce a diagnostic response.

\section{COMPLICATIONS}

Minor complications of carotid sinus massage include local discomfort or pain. Light-headedness or syncope may also occur. Serious complications, such as stroke or transient ischemic attack, are rare and have been estimated to occur at a rate of less than $0.5 \% .{ }^{12-14}$

The risk of stroke or transient ischemic attack can be minimized by observing the contraindications to carotid sinus massage. In very rare instances, atrial fibrillation and ventricular tachyarrhythmia may be induced as a result of extreme bradycardia. The consequences of these complications can be minimized by making sure that all materials required for resuscitation are at hand.

\section{SUMMARY}

Carotid sinus massage is frequently performed at the bedside in the diagnostic evaluation of syncope and in the diagnosis or treatment of paroxysmal supraventricular tachycardia. A careful preprocedural evaluation is needed to make sure

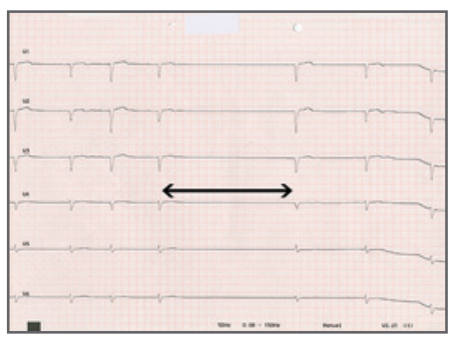

Figure 2. Carotid Sinus Massage Resulting in a Ventricular Pause of 3.5 Seconds.

When evaluating the cause of syncope, it is necessary to reproduce the patient's symptoms to some degree and to induce a ventricular pause that lasts 3 seconds or more (doubleheaded arrow) or a drop in systolic blood pressure of $50 \mathrm{~mm} \mathrm{Hg}$ or more in order to confirm a diagnosis of carotid sinus syndrome.

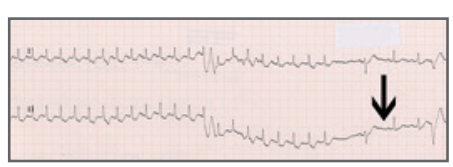

Figure 3. The Use of Carotid Sinus Massage in the Treatment of Atrioventricular Nodal Reentrant Tachycardia or Tachycardia Mediated by an Accessory Pathway.

The success of the procedure is indicated by the restoration of sinus rhythm (arrow).

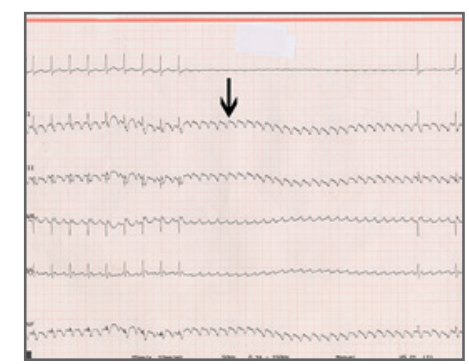

Figure 4. The Use of Carotid Sinus Massage in Revealing an Otherwise Hidden Atrial Flutter.

In some instances, carotid sinus massage may produce a transient slowing of the ventricular rate that can reveal otherwise undetected atrial activity, such as the underlying atrial flutter characterized by atrial $\mathrm{F}$ waves (arrow) shown here. 
that there are no contraindications to the procedure. All patients must be properly prepared and closely monitored during the massage. The physician must be aware of and able to manage rare but potentially serious complications.

No potential conflict of interest relevant to this article was reported.

Disclosure forms provided by the authors are available with the full text of this article at NEJM.org.

\section{REFERENCES}

1. Blomström-Lundqvist C, Scheinman MM, Aliot EM, et al. ACC/AHA/ESC guidelines for the management of patients with supraventricular arrhythmias - executive summary: a report of the American College of Cardiology/American Heart Association Task Force on Practice Guidelines and the European Society of Cardiology Committee for Practice Guidelines (Writing Committee to Develop Guidelines for the Management of Patients with Supraventricular Arrhythmias) developed in collaboration with NASPE-Heart Rhythm Society. J Am Coll Cardiol 2003;42:1493-531.

2. Neumar RW, Otto CW, Link MS, et al. Part 8: adult advanced cardiovascular life support: 2010 American Heart Association guidelines for cardiopulmonary resuscitation and emergency cardiovascular care. Circulation 2010;122:Suppl 3:S729-S767.

3. The Task Force for the Diagnosis and Management of Syncope of the European Society of Cardiology (ESC). Guidelines for the diagnosis and management of syncope (version 2009). Eur Heart J 2009;30:2631-71.

4. Schweitzer P, Teichholz LE. Carotid sinus massage: its diagnostic and therapeutic value in arrhythmias. Am J Med 1985;78:645-54

5. Toorop RJ, Scheltinga MR, Moll FL, Bleys RL. Anatomy of the carotid sinus nerve and surgical implications in carotid sinus syndrome. J Vasc Surg 2009;50:177-82.

6. Strickberger SA, Benson DW, Biaggioni I, et al. AHA/ACCF Scientific Statement on the evaluation of syncope: from the American Heart Association Councils on Clinical Cardiology, Cardiovascular Nursing, Cardiovascular Disease in the Young, and Stroke, and the Quality of Care and Outcomes Research Interdisciplinary Working Group; and the American College of Cardiology Foundation: in collaboration with the Heart Rhythm Society: endorsed by the American Autonomic Society. Circulation 2006;113:316-27.

7. Krediet CT, Parry SW, Jardine DL, Benditt DG, Brignole M, Wieling W. The history of diagnosing carotid sinus hypersensitivity: why are the current criteria too sensitive? Europace 2011;13:14-22.

8. Brignole M, Alboni P, Benditt DG, et al. Guidelines on management (diagnosis and treatment) of syncope — update 2004. Europace 2004;6:467-537.

9. Waxman MB, Wald RW, Sharma AD, Huerta F, Cameron DA. Vagal techniques for termination of paroxysmal supraventricular tachycardia. Am J Cardiol 1980;46:655-64.

10. Epstein AE, DiMarco JP, Ellenbogen KA, et al. 2012 ACCF/AHA/HRS focused update incorporated into the ACCF/AHA/HRS 2008 guidelines for device-based therapy of cardiac rhythm abnormalities: a report of the American College of Cardiology Foundation/American Heart Association Task Force on Practice Guidelines and the Heart Rhythm Society. J Am Coll Cardiol 2013;61(3):e6-e75.

11. European Society of Cardiology (ESC). 2013 ESC guidelines on cardiac pacing and cardiac resynchronization therapy: the Task Force on Cardiac Pacing and Resynchronization Therapy of the European Society of Cardiology (ESC): developed in collaboration with the European Heart Rhythm Association (EHRA). Europace 2013;15:1070-118.

12. Munro NC, McIntosh S, Lawson J, Morley CA, Sutton R, Kenny RA. Incidence of complications after carotid sinus massage in older patients with syncope. J Am Geriatr Soc 1994;42:1248-51.

13. Puggioni E, Guiducci V, Brignole $M$, et al. Results and complications of the carotid sinus massage performed according to the "method of symptoms." Am J Cardiol 2002;89:599-601.

14. Davies AJ, Kenny RA. Frequency of neurologic complications following carotid sinus massage. Am J Cardiol 1998;81:1256-7.

Copyright (c) 2017 Massachusetts Medical Society. 